\title{
Exclusões do cânone: Gustavo Barroso e o pré-modernismo brasileiro
}

\author{
Exclusions from the canon: Gustavo Barroso and \\ the brazilian pre-modernism
}

\author{
Cláudio do Carmo GONÇALVES \\ Universidade Estadual de Santa Cruz (UESC)
}

RESUMO: Este artigo é uma reflexão sobre a formação do cânone literário brasileiro, especialmente na sua formulação moderna do início do século XX, quando mesmo um pré-modernismo, incorporado pela tradição literária mais recente, atua politicamente no sentido de excluir de seu repertório autores que não se vinculam à sua expectativa estética. Para tanto a atuação do intelectual, escritor polígrafo e, sobretudo, homem de letras, Gustavo Barroso e de sua relação com o Prémodernismo brasileiro, considerando categorias como capital cultural e capital pessoal, conforme Pierre Bourdieu (2010), demonstram de que modo o autor é deslocado para a margem do período numa exclusão tácita.

PALAVRAS-CHAVE: Cânone literário. Pré-modernismo. Gustavo Barroso. Capital pessoal.

ABSTRACT: This article is a reflection on the formation of the Brazilian literary canon, especially in its modern formulation of the early twentieth century, when even a pre-modern literary tradition built by newer acts politically to exclude from his repertoire authors not linked to their aesthetic expectations. Therefore the role of intellectual, writer polygraph and foremost man of letters, Gustavo Barroso and his relationship with the Pre-Brazilian modernism, considering categories such as personal capital and cultural capital, as Pierre Bourdieu (2010), demonstrate how the author is moved to the edge of the exclusion period in a tacit.

KEYWORDS: Literary canon. Pre-modernism. Gustavo Barroso. Personnel capital. 
$\mathrm{Na}$ tradição literária brasileira, seguindo as conclusões observadas em Antonio Candido (1975), há uma clara disposição no sentido de se relatar a história da narrativa ficcional através de textos e autores que esteticamente se filiem ao discurso mais rotineiro. Um tipo de discurso que estruturado em aspectos tão díspares quanto complexos assumem a feição de um cânone, ou seja, de uma narrativa estabelecida e aceita por todos.

Não há propriamente como distinguir onde e como o cânone é instituído, mas sabe-se que entre os gregos, na Antiguidade, o cânon ou módulo era um elemento estético resultado do equilíbrio e predominância da razão do ser humano representado nas artes. Perseguia-se o chamado belo ideal, que desta forma inferia um modelo a ser seguido por todos. Assim, a representação escultórica ideal e racional era aquela assentada na proporção exata ou ideal entre a parte e o todo do corpo humano.

Deste modo as primeiras esculturas são realizadas à base de uma medida única que divide o corpo humano. Inicialmente acreditava-se que esta proporção se dava na medida de cinco cabeças, ou seja, a escultura ideal deveria ter o tamanho proporcional ao resultado de cinco cabeças. Este número ganha contornos de precisão com o escultor Policleto, cerca de 400 a.C., que consegue dar a noção de sete cabeças para um corpo perfeito, o que posteriormente é acrescido para oito cabeças pela inovação de Lísipo que então parece alcançar a perfeição, dando certa graciosidade às suas formas quase femininas. (D'AQUINO, 1980, p. 11)

Qualquer reflexão sobre a formação do cânone literário brasileiro, especialmente na sua formulação moderna do início do século $\mathrm{XX}$, deve situar necessariamente de que cânone estamos falando, bem como a maneira que este cânone se apresenta, e quais os critérios e/ou condições que fazem ser o cânone indiscutível.

A primeira pista nasce do texto algo polêmico do crítico norte-americano Harold Bloom(1995) que em obra que causou grande reação de crítica e público busca reafirmar o cânone ocidental e abre uma discussão em relaçao àqueles que querem 
desestabilizar o cânone. A estes ele nomeia como o coro dos ressentidos, que em linhas gerais englobaria as novas teorias contemporâneas tais como os estudos culturais, multiculturalismo e feminismo.

Bloom (1995) argumenta que o estranhamento está na raiz da construção do poeta como canônico, um estranhamento que se confunde com originalidade. Assim, o processo de influência é fundamental neste processo, pois quanto maior a capacidade de influenciar seus predecessores maior será a originalidade, o estranhamento que condiciona o poeta como canônico. Em última análise Bloom salienta que é a primazia da estética como concepção literária que guia por séculos o cânone.

Está claro que a repercussão das afirmações do crítico ganharam grande destaque, sobretudo quando estabelece a defesa do cânone através de um outro cânone de matriz europeia-norteamericana, mas ao nos debruçarmos sobre seus argumentos talvez o mais falho seja a convicção da formação canônica, que ao nosso ver, não se dá apenas e tão somente pela originalidade e essa capacidade singular de influenciar.

$\mathrm{Na}$ formação do cânone há fatores estéticos sim, que possivelmente são notáveis e representam a força mais eficaz nesta construção, mas não se pode negligenciar outros tantos aspectos que configuram igualmente um forte apelo a essa construção, tais como aspectos políticos, ideológicos e históricos e outros tantos que fogem à compreensão objetiva, naquilo que Walter Benjamin (1992) nomeou como aura, ou seja, aquela equidistância do objeto que o torna tão perto e tão longe ao mesmo tempo. Esse algo mais correspondente à aura não se controla e é indeterminado, não se sabe quando e como vai aparecer.

A história literária é pródiga em autores que, de alguma forma, capitalizaram os traços ideológicos e políticos relacionados à sociedade. De outra forma, o que poderia ser um sinal negativo em seus perfis literários sob a acusação de um determinismo, é incorporado como uma defesa positiva, o que fez com que ganhassem lugar no panteão literário do cânone. Alguns são 
cânone em seu próprio tempo apenas, numa espécie de cânone efêmero; outros são cânones que ultrapassam as medidas de seu tempo e passam a ser modelos para outras gerações que irão segui-los em admiração e tradição.

A tradição literária brasileira nos legou alguns desses autores cânonicos, sobretudo a partir do século XIX, quando se formam as condições de influência e aprofundamento de um capital social e político que possa ser exercitado e consolidado. É notório o prestígio alcançado por escritores tais como Machado de Assis, que se vale deste capital social para, entre outras atitudes, se apresentar como um dos fundadores e primeiro presidente da Academia Brasileira de Letras. Tal prestígio não se dá tão somente pela qualidade de seus textos, embora seja um fator importante, mas também pelas relações cultivadas e mantidas junto a outros tantos escritores e intelectuais da época. Os casos do Joaquim Manuel de Macedo, o doutor Macedo, bem como de José de Alencar também são notáveis exercícios de influência e camaradagem que forçam o estabelecimento do cânone.

Essa tradição canônica, como atestamos, continua na virada do século XIX para o século XX, incluindo uma narrativa que tem nos períodos literários um forte componente de articulação. Assim é que Romantismo, depois Realismo, foram períodos literários decisivos na formação do cânone brasileiro, que viria a conhecer, somente no século XX, um movimento literário organizado sob bases idealistas cuja eficácia na formação canônica é notória, causando uma espécie de paradigma a partir de então. Sabe-se que enquanto movimento estético-literário, o modernismo brasileiro postulou algumas bandeiras contrárias ao cânone estabelecido e identificado com o passado. Mas também hoje não se discute que o próprio Modernismo fez algumas conveniências históricas no sentido de ser aceito pelo cânone, talvez a atitude mais exemplar neste sentido tenha sido o alinhamento a Graça Aranha, que acaba, simbolicamente, avalizando o projeto moderno.

Com a vitória da estética modernista, o que se segue não é propriamente uma recusa ao cânone e nem mesmo uma ratificação 
dos postulados contrários ao passado, mas sim uma espécie de cânone às avessas, pois os modernos que reagiam contra uma estética dominante, passaram a ser eles mesmos esta estética, cujo olhar passou a orientar toda e qualquer produção literária a partir da década de 1920.

Com esta vigência totalizadora da estética modernista, vem também uma vigência crítica que culmina com a formulação de um período imediatamente anterior ao modernismo, hoje conhecido como pré-modernismo.

Assim, em realidade, o Pré-modernismo é incorporado pela tradição literária mais recente, a partir do filtro moderno, e atua politicamente no sentido de excluir de seu repertório autores que não se vinculam à sua expectativa estética, formulando um cânone natural entre períodos literários.

$\mathrm{Na}$ conjuntura do Pré-modernismo brasileiro, há histórias de exclusão que se confundem com a própria história do período. Sabe-se que o Pré-modernismo é um período da historiografia literária brasileira que se encontra ainda repleto de obscuras interpretações que estão longe de torná-lo consenso. Outras literaturas nacionais não compreendem o período inicial do século XX como pré-modernista. França, Inglaterra e Portugal, para citarmos os necessários, vivem uma extensão simbolista que desemboca no Modernismo de inclinação futurista. Portugal, especialmente, vê chegar o seu quinhão modernista em $1915 \mathrm{em}$ plena vigência pré-modernista brasileira. Essa particularidade brasileira faz com que o pré-modernista esteja um tanto à sombra dos embates de visibilidade que pontuam o movimento dinâmico dos períodos literários.

Esses primeiros anos do século XX no Brasil apresentaram uma diversificada e vasta produção literária. As duas primeiras décadas marcam um longo período de transição entre o que era passado e o que seria já moderno, expressando a atmosfera do fin-de-siècle ocidental, que constitui certo sentimento de tempos fundidos, em que não se percebe bem o século que acabou e o que se inaugura, em uma operação típica de desintegração, no que 
Antonio Saraiva (1999, p. 133) denomina "esquina do século". Decorrem deste período as mais variadas tendências e estilos literários, desde o conservadorismo parnasiano às inclinações modernas dos simbolistas, considerando também autores regionalistas e seu apelo político, culminando com os mais radicais, que incorporavam a vanguarda europeia, então em plena efervescência.

$\mathrm{O}$ que se convencionou chamar de Pré-modernismo no Brasil, então, não constitui uma "escola ou estilo literário", ou seja, não encontramos ali um grupo de autores afinados em torno de um mesmo ideário, seguindo determinadas características epocais e estilísticas. Deste modo, está claro que o Pré-modernismo é, assim, um termo genérico que designa a produção literária de autores das mais variadas experiências e atitudes estéticas, tais como Euclides da Cunha, Lima Barreto, Graça Aranha, Monteiro Lobato e Augusto dos Anjos.

Embora não apresentasse características coletivas orgânicas, o Pré-modernismo pode ser alinhado a uma base comum a partir de fortes inclinações individuais, por vezes até antagônicas, de que é exemplo o caso da ruptura com o passado e com o academicismo, principalmente através da linguagem, conforme o caso de Augusto dos Anjos e de Lima Barreto, este um ironista da linguagem pomposa dos escritores da época.

Outra corrente bastante constante no período é a que reúne escritores em torno da denúncia da realidade nacional e nega o Brasil literário herdado do Romantismo e do Parnasianismo, em uma expressão, recusa do passado, inserindo, de outro modo, o "Brasil não-oficial" dos caboclos, do nordeste, dos subúrbios, bem como acrescentando à literatura os tipos humanos marginalizados, tais como o sertanejo nordestino, o caipira, os funcionários públicos, os mulatos.

Há ainda uma forte ligação com fatos políticos contemporâneos, o que diminui a distância entre a realidade e ficção, traduzida em obras como Triste fim de Policarpo Quaresma, de Lima Barreto; Os sertões, de Euclides da Cunha; 
Cidades mortas, de Monteiro Lobato; e Canaã, de Graça Aranha, todas matizadas pelo olhar acerca do cotidiano, e cujos enredos diferem quanto aos objetivos, mas que, na essência, tematizam a cor local do panorama político daquelas primeiras décadas.

Deste modo, o Pré-modernismo aponta para uma "excrescência" da história literária, revigorado pelo olhar rigoroso da crítica dos escritores concretistas nos anos 50/60, que encontrou na aparente desformidade da produção do período uma razão de coesão que os unia. Assim, Lima Barreto e Graça Aranha, entre outros, em suas decantadas diferenças, são próximos temporalmente e leem seu tempo como produtores de cultura.

Mas há um fator que não pode ser negligenciado: ao se fazer a recuperação pré-modernista através de seus autores e de sua produção, observa-se um recorte que privilegia autores legitimados posteriormente, sobretudo pelos modernos, colocando no limbo outros tantos que foram enquadrados nesta ótica. Não sem propósito, escritores como Pedro Kilkerri, Sousândre e, mais recentemente, João do Rio, têm seus nomes inscritos na mais pura tradição literária brasileira.

No entanto, ao que parece, o Pré-modernismo, da mesma forma que sofreu um longo período de exclusão ${ }^{1}$, teve papel preponderante na antecipação da estética dominante que mais tarde viria a se configurar com o Modernismo.

O caso mais rumoroso dessa exclusão talvez seja o de Gustavo Barroso que, tendo vivido todo o período pré-moderno e moderno, é alijado completamente da estética, tanto de um quanto do outro período. Alguns sinais, não tão claros, podem ajudar a compreender o porquê dessa exclusão e mostrar o significado implícito presente nesta atitude política.

\footnotetext{
${ }^{1}$ A crítica mais atuante do período, que vai dos anos 20 aos anos 70 , na maior parte ignora o Pré-modernismo, conforme se vê nos escritos de Lúcia Miguel Pereira, Antonio Candido e Afrânio Coutinho, por exemplo. Há uma pequena referência em Alfredo Bosi, em seu clássico História concisa da literatura brasileira. Vale notar que Bosi dedicou ao período um estudo, intitulado $O$ Pré-modernismo (1966).
} 
O primeiro sinal que poderia servir de argumento talvez se devesse à inadequação estética de Barroso ao período prémoderno. Ora, sabemos que a melhor crítica insinua uma gama formidável de tendências que pululavam naquele período, que consegue abarcar desde um Coelho Neto, vindo da tradição rigorosa do Parnasiansismo, ao "quase-moderno" Lima Barreto. Barroso, no entanto, parece não se enquadrar no quadro vasto das temáticas do fin-de-siècle, embora contemplasse uma vasta produção, como intelectual polígrafo que era, e cuja dimensão era verificada pelo enorme prestígio intelectual de que gozava à época. Sua produção abarcava contos, estórias folclóricas, História, romances regionalistas, crônicas e ensaios de diversos matizes, além da atuação destacada no cenário intelectual e cultural brasileiro, culminando com a fundação e direção do Museu Histórico Nacional, a qual deve ser destacada como forte instrumento simbólico na aquisição do capital político da época e como referência para a constituição cultural relativamente mais vigorosa do autor no campo cultural, o que alcançou na sua condição de escritor.

A criação do Museu, em 1922, é um instrumento capaz de aglutinar todas as propostas e soluções de um Brasil grande e identificado com as conquistas das classes políticas e hegemônicas que constituem o panorama nacional. Com efeito, no Museu vão estar expostos objetos símbolos da nação reluzente, com a interferência direta das famílias que compunham a teia das relações sociais da elite. É o capital social, em consonância ao capital familiar, que estabelece as condições que asseguram uma bem sucedida evidência de Barroso, que com seu enorme talento se apropria dos discursos simbólicos nem sempre visíveis da nação no início do século para se posicionar na condição de intelectual e literato de destaque, respeitado por seus pares.

É interessante notar que, mesmo no estabelecimento da tradição modernista, o papel de Gustavo Barroso permanece de forma um tanto acanhada, embora sendo objeto de respeito e talvez curiosidade, o que demonstra o interesse de Mário de 
Andrade por sua obra, em plena eclosão modernista ( CARMO, 2002).

Hoje, sabemos que o projeto estético modernista passava por uma guerra simbólica de dimensões amplas, que envolvia a memória, as instituições e a artes. No entanto, é desconhecido que tenha havido um projeto estético pré-modernista nestes moldes, sobretudo em virtude de uma rara dificuldade de se pensar o Prémodernismo de modo orgânico, como um período literário. Mas é aí que reside talvez a compreensão mais complexa do período.

O Pré-modernismo também apresentou uma guerra estética que, como toda guerra, seja real ou simbólica, apresenta vencedores e vencidos. Embora as condições de organização da arte e da literatura não fossem apropriadamente coesas, como vimos na pouca identificação entre autores e obras, o Prémodernismo era produto estético de um capital político e social que confrontava o cânone e a margem. O inusitado está em identificar quem faz parte de um e de outro.

Se é certo que autores canônicos como Graça Aranha, Euclides da Cunha, Coelho Neto, e mesmo outros que compõem o cenário pré-moderno, controlam o capital literário, é certo também que um Lima Barreto é colocado estrategicamente fora, para estar dentro. Fazia parte do sistema simbólico pré-modernista a exclusão deste, bem como a de outros nomes menos óbvios, como Théo Azevedo e João do Rio, aos quais o enfrentamento era necessário e fazia parte do jogo que nutriria o status quo prémodernista.

Neste quadro, Gustavo Barroso é um caso peculiar, pois desempenha a antinomia previsível em relação ao prémodernismo, embora não tivesse exatamente o physique du rôle do excluído, ao mesmo tempo em que não se alinhava ao canône. Por outro lado, Barroso não representava um aliado funcional do cânone, mas também não fazia parte da margem prevista.

O lapso de tempo pré-moderno revela o jogo de interesses capitaneado pelo capital social/familiar. Tornara-se impossível a não-convivência da experiência das letras com a manifestação 
política, o que consolidaria uma carreira bem sucedida, de heranças reveladoras. Tal herança deveria ser marcada pela formação de Gustavo Barroso em Direito - o chamado bacharel -, pela escritura de alguns livros e, finalmente, por seu ingresso na carreira pública.

Torna-se evidente a posição de articulação que movia os interesses e as políticas locais e nacionais. Enquanto, a partir do Modernismo, o movimento é o do homem de letras buscando eco na vida pública, as duas primeiras décadas do século XX marcam o registro da República das Letras, em que a ressonância de um homem público se condiciona à escritura como mais uma etapa na sua herança social e política. Assim, as letras dariam a Gustavo Barroso certa legitimidade perante seus pares e diante das próprias classes subalternas.

Sintomático é o recurso das memórias e crônicas que atestam o recurso. Nestas formas se encontra a possibilidade de, tangenciando a ficção, estabelecer suas próprias verdades, o que se consubstanciava no relato opinativo sobre suas vivências, ao mesmo tempo em que se constituia, a partir da experiência individual, a autorização ao coletivo.

Meu pai é de ferro. Muito lido, muito culto e muito paradoxal ao mesmo tempo, dispõe de uma memória formidável [...] Ana Guilhermina foi minha mãe. Diplomada com as mais altas notas pela Escola Nacional de Hamburgo, era uma moça perfeita. (BARROSO, 2000, p. 39)

A trajetória de Gustavo Dodt Barroso se inscreve de maneira exemplar no que podemos ilustrar como sendo uma ficção orgânica, dialogando com cautela sobre o conceito de Gramsci. Se o intelectual se define por sua função social, na visão gramsciana, ou, para sermos mais adequados, à função que ele exerce em um tipo de civilização ou produção dada, a lógica que prevaleceu naquelas primeiras décadas é perfeitamente verossímil, pois se tratava, a rigor, da lógica do capital social em nome da razão hegemônica. 
O intelectual orgânico, no contexto apresentado, desempenha o papel de consolidação da ideologia dominante, utilizando formas prestigiosas que estendem sua ressonância às demais classes. Note-se que as produções literárias representadas nas primeiras décadas obedecem à lógica da norma e exclusão, o que viria a ser apropriado pelo próprio período posterior: o modernista.

Nas artes e na cultura assistia-se a um saudosismo corroborado pela culminância notável da exposição internacional de 1922, com a implantação de projetos e concursos que privilegiavam este tipo de expressão. Não nos esqueçamos de que formas arquitetônicas conservadoras e passadistas eram as grandes vedetes do momento, em clara dualidade com os discursos de modernização que já se pronunciavam. O sentido encontrado em tais conservadorismos, em clara oposição às correntes progressistas, encontra eco na busca de um país com raízes genuínas, em que os estilos passadistas eram o ápice do conceito de nação que essas correntes conservadoras buscavam delinear.

O conservadorismo da arte e da cultura encontra um pseudo paradoxo na experiência de se valer de um discurso utilitário, em que as formas apregoadas deveriam obedecer a uma consequência de valor social, ou seja, deveriam ser instrumentos de mudança social.

Note-se, no entanto, que este discurso inclina-se sobre sua própria inércia, pois as mudanças veiculadas impunham certo critério, condicionando-as à própria experiência. Os modelos de civilização presentes no imaginário das classes que dominavam a cena política e social ainda eram externos, ainda europeus por excelência. Por outro lado, no entanto, ocorreu uma canalização ambígua no plano cultural. Os "bons modos" a serem seguidos no plano comportamental contemplam a classe dominante e deveriam servir de instrução às classes subalternas para que o país pudesse enfim angariar projeção e entrar no rol das civilizações modernas.

$\mathrm{O}$ mito da nação moderna era uma das referências e 
os portadores deste discurso frequentemente eram aqueles que dominavam a cena política e social. Gustavo Barroso, em determinado, momento diz: "Somos o povo que menos guarda e, portanto, menos estima as coisas do passado. Necessitamos ser educados" (BARROSO apud DUMANS, 1947, p. 37). Na passagem fica evidente a devoção para com a educação do povo, dimensão arguida com ênfase extraordinária nos discursos intelectuais e que no extremo vislumbravam o sentimento de responsabilidade e liderança de que estes se incumbiam.

As propostas enfatizavam a mudança da realidade brasileira em relação aos modelos exteriores, assim como se condicionava, entre tantos argumentos, a condução deste processo pelo homem de letras, nesta altura perfeitamente engajado na função.

Depreende-se a inclusão de uma elite na representação destes anseios. O que parece inusitado, no entanto, é a configuração desta elite e como se manifestam as formas de apropriação.

$\mathrm{O}$ prestígio dos intelectuais era o passaporte para a instrução civilizatória. Por meio de uma erudição mundana, aqueles intelectuais dominavam a cena, aliando-se aos detentores do poder instituído. Aliás, estes se originam da mesma raiz, na qual o capital familiar é a senha para a progressão social e política.

Gustavo Dodt Barroso nasceu em Fortaleza, Ceará, em 1888. Teve uma formação "necessária" a todo pretendente a homem de letras e intelectual. Estudou Direito e se notabilizou nas diversas atividades desenvolvidas na cena intelectual. Como escritor produziu diversas formas de escrita tais como contos, romances e ensaios; ainda atuou como jornalista, teatrólogo, crítico literário e folclorista, alcançando, sem dificuldades, a Academia brasileira de Letras, da qual seria presidente por duas ocasiões. Barroso lança mão da estratégia comum à intelectualidade que pontifica certa corrente nos anos 20. Vindo de família tradicional do Nordeste, porém decadente, consegue se estabelecer no círculo dirigente do Rio de Janeiro, estratégia esta que culminaria com as várias posições de destaque nos mais diversos postos da administração pública, inclusive exercendo missões diplomáticas. 
A conjuntura assegura aos intelectuais a colocação no ambiente de poder da classe dirigente, mediante o vínculo maior ou menor de suas famílias com os detentores do poder. A proximidade, aliás, em maior ou menor grau, desencadearia o processo de prestígio desfrutado na teia das relações sociais. Sergio Miceli (1979, p. 23) pontua: "As profissões intelectuais constituem um terreno de refúgio reservado aos herdeiros das famílias pertencentes à fração intelectual e, sobretudo, aos filhos das famílais em declínio".

No campo das letras, não era sem propósito a relação que se estabelecia. Os intelectuais de berço davam continuidade a uma tradição de produção voltada para um variado conjunto de obra. A despeito do que se poderia supor, as obras destes intelectuais polígrafos, da qual Gustavo Barroso é um exemplo nítido, não se restringem a seus pares. Elas alcançam níveis de vendagem notáveis, com várias edições sucessivas. São notórias suas relações com a família Calmon, que ocupava especial dimensão na $1^{\text {a }}$ República.Tais relações propiciaram a Barroso a Direção do Museu Histórico Nacional, que lhe foi oferecida pela influência familiar junto aos governantes da República e que lhe daria projeção nacional.

O museu é a casa do Brasil, pela perpetuidade de sua exposição e o sentimento nacional dela. V.Exa. disto se certificará, se houver por bem aceitar este oferecimento, concorrendo, com a aludida doação, para a consagração conjunta, de um grande nome e de uma época social e administrativa a esta ligada. (Barroso apud ABREU, 1990, p.24)

A partir de então o próprio Gustavo Barroso passa a ocupar invejável papel de prestígio na República Velha, graças às colaborações à imprensa, notadamente à revista Fon-Fon, da qual foi diretor, a partir de 1916, e por conta das diversas conferências que realiza, tematizando o folclore, a guerra, a língua, enfim, uma gama de erudição mundana que o afirmava como grande vedete literária do período, sendo que a contingência do período produz um conjunto de obras sob o título de memórias, da qual os 
polígrafos, mais uma vez, são os grandes detentores da expressão.

Em 1936, Barroso publica o livro intitulado Brasil, colônia de banqueiros: história dos empréstimos de 1824 a 1834, cuja receptividade na imprensa nacional e internacional assevera o prestígio do intelectual, como podemos depreender em chamadas reproduzidas na capa da própria edição, como estes trechos do New York Times de Nova York: "O sr. Gustavo Barroso, um dos chefes do Integralismo, provou no seu recente livro que o Brasil tem sido um paraíso dos banqueiros, uma colônia de banqueiros." Ou ainda do Jornal da Noite, editado na cidade de Santos em São Paulo:

O sr. Gustavo Barroso, dentro dos quadros do mais sadio nacionalismo, provou documentadamente que o Brasil tem sido, desde a independência nas margens do Ipiranga, uma verdadeira colônia dos banqueiros de além-mar.

O aparecimento da memória como gênero literário naquele momento pode ser relacionado à capacidade de autorização daqueles intelectuais, que buscavam, através de suas experiências pessoais e de outras, orais, configurar o modelo necessário à instrução da nação, o chamado mito fundacional. Note-se que não se distingue a vida literária ou intelectual da vida social e política. A extensão se fazia nítida. A quase ficção, expressada através da memória como gênero impuro, se realiza em consonância com os aspectos ideológicos. Não é sem propósito que o tom opinativo se misture, embora dentro de uma perspectiva romanceada, ao próprio tom confessional que caracteriza as memórias.

As memórias encerram o intuito maior de testemunho de uma época e de documento histórico, destarte conferindo um status intelectual sobremaneira a seus autores, pois evidenciam toda uma trajetória ligada ao poder público. Assim, a memória pessoal se relaciona à memória coletiva e, nesse sentido, com todo o imaginário ideológico que se possa entrever. Se o homem de letras naquele momento estava imbuído, através de sua reputação, em articular a defesa de seus pares, que configuravam a classe dominante, não é menos verdade que aquela defesa se 
instrumentalizava através da receita de um modus vivendi em que o imaginário coletivo e subalterno pudesse se espelhar. É recorrente o discurso didático de Barroso:

Porque não o temos ainda, precisamos criar o culto de nossas tradições especialmente das tradições militares. Sem o amor do passado e a lição dos feitos antigos, não pode haver nacionalidade. Amar a história é amar a terra. [...] Devemos executar esse programa materialmente - fomentando o desenvolvimento físico e o aparelhamento militar; espiritualmente - incutindo em todos os brasileiros a religião do passado, que é a alma mesma da pátria (BARROSO apud DUMANS, 1947, p. 37).

O passado anotado e a recuperação dos grandes feitos sob a forma de uma memória consagrada à nação são (re)afirmados, ao mesmo tempo em que se constrói um imaginário assentado na memória glorificadora, solidificando-se a instrumentalização desta herança através da intermediação da elite. E o papel do homem de letras neste momento revela-se na legitimidade que irá conferir às narrativas de memória, as quais fazem o elo do subjetivo ao coletivo, fim maior da elite escriba.

A reconstituição pessoal nada mais é que o pretexto, a título de se mostrar a trajetória exemplar, para se inscrever como personagem fundamental nos destinos da nação. Assim, toda a visão política e social está condicionada às interferências óbvias que se atribuem estes memorialistas oficiais.

As elites contribuíam, desta forma, para a sua representação máxima nos "lugares memória". A lógica desta representação se dá em níveis de absoluta hierarquia. Através de seus nomes, públicos, deveria se expor objetos, relíquias que cultuassem o passado de glórias e assim, cada vez mais, sintetizar o aspecto de identidade nacional.

As crônicas de Barroso, como de resto todo conjunto de sua obra, apontam para o resgate da memória nacional e, no extremo, para a formação incondicional relacionada aos sujeitos da mentalidade brasileira. 
Como uma forma invisível que aquece e mantém o jogo de poder, as estratégias repousadas no capital social servem de possibilidades legitimadoras na condução política e se valem da memória institucional como narrativas privilegiadas nesta legitimação. Ao que parece, o inócuo lugar destinado à República das Letras, ou às decadentes famílias tradicionais e aos políticos de segunda classe, longe de reafirmar uma representação tout court, configuram formas definitivas e pouco nítidas de instaurações discursivas e, num extremo, de estabelecimento de realidades.

Assim, Gustavo Barroso, o polígrafo, homem de letras que cultivou um enorme capital social durante a primeira república, tendo sido o artífice e principal diretor do Museu Histórico Nacional, além de se movimentar com enorme desenvoltura nas elites letradas do início do século, não consegue transformar esse capital e prestígio em cânone, refutado que foi pelo filtro moderno e, em sua esteira, pré-moderno. Barroso, ao mesmo tempo que representa, também se afasta do Pré-modernismo brasileiro a um só tempo, não se ajustando ao cânone orgânico colocado em evidência pelos modernistas brasileiros, e nem ao elemento conflituante que serviria de contraponto ao aquecimento do período. Barroso, embora revestido do capital cultural e pessoal próprio de certa elite intelectual das primeiras décadas do século $\mathrm{XX}$, se coloca naquele entre-lugar, entendido como certo intermédio entre uma absoluta adequação e o deslocamento arbitrário a que relegou o olhar moderno e seus desdobramentos mais objetivos como foi o caso do âmbito pré-modernista.

\section{REFERÊNCIAS}

ABREU, Regina de. Tradição e modernidade: o Museu histórico nacional e seu acervo. Rio de Janeiro: IBPC, 1990. Cadernos museológicos, v.3

BENJAMIN, Walter. A obra de arte na era da reprodutibilidade técnica. In: Sobre Arte, Técnica, Linguagem e Política. Tradução de Maria Luz Moita. Lisboa: Relógio D’Água Editores, 1992. 
BLOOM, Harold. O cânone ocidental: os livos e a Escola do tempo. Rio de Janeiro: Objetiva, 1995.

BOSI, Alfredo. História concisa da literatura brasileira. 40. ed. São Paulo: Cultrix, 2002.

BOSI, Alfredo. O pré-modernismo. São Paulo: Cultrix, 1966.

BARROSO, Gustavo. Brasil colônia de Banqueiros: história dos empréstimos de

1824 a 1934. 5. ed. Rio de Janeiro: Civilização Brasileira, 1936.

. Coração de menino. Ceará: Ed. UFC, 2000.

BOURDIEU, Pierre. As regras da arte: gênese e estrutura do campo literário. Tradução: Maria Lúcia Machado. São Paulo: Companhia das Letras, 2010.

CANDIDO, Antonio. Formação da literatura brasileira: momentos decisivos. 5. ed. Belo Horizonte:ed. Itatiaia; São Paulo: EdUSP, 1975.

CARMO, Cláudio do. Fiçcões do patrimônio: raízes da memória em Gustavo Barroso e Mário de Andrade. Rio de Janeiro: Ágora, 2002.

D’AQUINO, Flávio. Artes plásticas I, Rio de Janeiro: Bloch: Fename, 1980.

DUMANS, Adolpho. A idéia da criação do Museu Histórico Nacional. In: PUBLICAÇÕES do Museu Histórico Nacional. Rio de Janeiro: Gráfica Olímpica, 1947.

MICELI, Sergio. Intelectuais e classe dirigente no Brasil (19201945). São Paulo: Difel, 1979.

SARAIVA, Antonio José. Iniciação à literatura portuguesa. São Paulo: Companhia das Letras, 1999.

Recebido em 31/03/2013.

Aprovado em 17/10/2013. 